\title{
Root canal treatment performed by Flemish dentists. Part 1 - cleaning and shaping
}

\author{
G. M. G. Hommez', M. Braem² \& R. J. G. De Moor ${ }^{1}$ \\ ${ }^{1}$ Department of Operative Dentistry and Endodontology, Ghent University, Ghent University Hospital, Dental School, Gent, and
}

${ }^{2}$ Department of Dental Materials, University of Antwerp, Campus RUCA, Antwerpen, Belgium

\begin{abstract}
Hommez GMG, Braem M, De Moor RJG. Root canal treatment performed by Flemish dentists. Part 1 - cleaning and shaping. International Endodontic Journal, 35, 000-000, 2002.
\end{abstract}

Aim The purpose of this study was to gather information on root canal treatment carried out by dentists working in Flanders (Belgium).

Methodology A questionnaire was handed to 312 dentists attending peer review sessions organized by the Flemish Universities. Basic information (age, gender, year of graduation, practice profile) and information on various issues relating to the cleaning and shaping of root canals was collected.

Results A total of 310 questionnaires were returned. The majority $(85.7 \%)$ of respondents categorized themselves as general practitioners; $25.7 \%$ mentioned a clinical interest or speciality in practice. Most practitioners $(64.5 \%)$ did not use rubber dam routinely during root canal treatment and performed treatment over two visits irrespective of the number of root canals. The majority of respondents $(82.4 \%)$ used sodium hypochlorite as an irrigant, but $10.6 \%$ did not know the concentration they used; EDTA was used by $61.6 \%$. The vast majority exposed a radiograph with an instrument of known length in situ to gauge the working length; only $3.6 \%$ relied on tactile sense; electronic root canal length determination was seldom used. Amongst the root canal instruments, K-files were used solely or in combination with other instruments by $60.3 \%$ of the respondents, reamers were used solely or in combination with other instruments by $55.4 \%$. The stepback technique was used by $31.2 \%$ of the participants, a combination of stepdown and stepback by $26.4 \%$, a reaming technique by $26.1 \%$ and the stepdown technique by $14.7 \%$. The majority were familiar with mechanical root canal instruments. Almost half of the practitioners believed their preparation technique could be improved; only $1.3 \%$ felt that their procedures were poor. Conclusions The results of this study indicate that the theoretical knowledge of dentists working in Flanders is good. However, the use of rubber dam remained low, half believed their preparation technique could be improved.

Keywords: Belgium, cleaning, dental practice, root canal treatment, shaping, survey.

Received 18 April 2001; accepted 16 October 2002

\section{Introduction}

Whenever postgraduate teachers discuss with practitioners the subjects they would like to see covered in courses, endodontics is often mentioned. Attendees on such courses generally wish to learn how to make

Correspondence: Prof. R. De Moor, Department of Operative Dentistry and Endodontology, Ghent University, Ghent University Hospital, Dental School, Ghent University, De Pintelaan 185, B-9000 Gent, Belgium (Tel.: +32 924040 00; fax: +32 924038 51; e-mail: roeland.demoor@ rug.ac.be). endodontic treatment quicker, easier and more successful (Carrotte 2000a).

It is known that the standard of root canal treatment carried out by general dental practitioners in Europe is poor (Saunders et al. 1997, Weiger et al. 1997, Marques et al. 1998, De Moor et al. 2000, Kirkevang et al. 2001, Hommez et al. 2002). It has been reported that one of the causes of such poor quality treatment in general practice may be that students graduate with a lack of expertise and a poor understanding of the principles involved (Dummer 1991). The recent European Society of Endodontology Undergraduate Curriculum 
Guidelines for Endodontology (ESE 2001) advocate that endodontics should be taught in clinical areas dedicated to that purpose, and that an appropriate number of cases should be treated. On the other hand, it could be argued that following some time in practice, the clinical expertise of dentists should have improved. In the present Belgian accreditation system, where courses in different subjects of dentistry have to be followed, the number of endodontic courses (most of them combining theory and preclinical exercise) should be sufficient to improve the performance of dentists. However, there is little evidence to demonstrate whether the information gathered during these courses is used in clinical practice.

The purpose of this study was to gather information on the nature of root canal treatment carried out by a group of dentists attending peer review sessions as a part of the programme of the Belgian accreditation system. Specific information regarding root canal cleaning and shaping was gathered on the basis of a questionnaire handed to dentists attending peer review sessions organized by the 'Interuniversitaire Samenwerking' (Inter University Cooperation of the Flemish Universities). The aim of the questionnaire was not only to collect baseline data, but also to determine the endodontic knowledge of dentists. Furthermore, it was hoped to gain an insight into potential problems regarding endodontic treatment procedures that could explain the present standard of root canal treatment carried out by general dental practitioners.

\section{Materials and methods}

A total number of 312 dentists who attended peer review sessions in the year 2000, organized by the 'Interuniversitaire samenwerking' (Inter University Cooperation of the Flemish Universities), i.e. the Universiteit Gent/Ghent University (RUG), the Katholieke Universiteit Leuven/ Catholic University of Leuven (KULeuven), the Vrije Universiteit Brussel/Free University of Brussels (VUB), the Universiteit Antwerpen/University of Antwerp (UA, RUCA), the Limburgs Universitair Centrum (LUC) and the Katholieke Universiteit Leuven Campus Kortrijk (KULAK), were asked to complete a questionnaire at the beginning of a peer review session. The questionnaires were anonymous. Of all Flemish dentists, 60\% participated in peer review sessions that were part of the official accrediting system (Government figures supplied by the 'Rijksdienst voor Ziekte- en Invaliditeitsverzekering').

Part one of the questionnaires covered personal information: university of graduation, years of practical experience, gender, part-time or full-time occupation, and if applicable, whether a particular clinical speciality was practised.

Part two of the questionnaire covered general information regarding root canal treatment: the use of rubber dam; the number of root canal treatments per week; the number of visits for one, two, three and four canals; the frequency of treatment of the fourth canal in maxillary first and second molars and the frequency of C-shaped canals in mandibular molars.

In part three the practitioners were asked about their methods for cleaning and shaping canals and the products and materials used. The following topics were covered: canal irrigants and chelators, working length determination, instruments and technique used for canal preparation.

When a list of possible answers was given, the practitioners were invited to choose the answer that best fitted their clinical practice. In most of these cases the range of answers was well defined so that there was no need to add additional responses. Space was provided when additional comments were necessary in the event of the usual practice not being adequately covered by the choice given.

One operator using EXCEL 2000 (Microsoft Corporation, Redmond, WA, USA) processed all questionnaires. For the detailed comparison, the sample was divided in groups according to years of practical experience or the years since graduation as follows: group 1, up to 5 years; group 2, 6-10 years; group 3, 11-15 years; group 4, 1620 years; group 5, 21-25 years and group 6, more than 25 years.

\section{Results}

Of the 312 questionnaires distributed, only two were not completed, giving a completion rate of $99.4 \%$. Three questionnaires were discarded because the respondents did not perform endodontic treatment.

\section{General information}

The majority (99.0\%) of practitioners graduated from one or other of the three Flemish universities (RUG, KULeuven,VUB). Fifty-one percent were males, 49\% were females. Almost half the female practitioners, whereas only a few male practitioners worked part-time. Most of the practitioners worked in full-time practice $(77.2 \%)$.

The distribution of the respondents by time since graduation in relation to the university of graduation is shown in Table 1. Table 2 gives an overview of the 
Table 1 Distribution of the respondents according to the years of qualification and the dental school

\begin{tabular}{llllllll}
\hline & \multicolumn{2}{l}{ Years of qualification } & & & & \\
\cline { 2 - 6 } Dental school & $0-5$ & $6-10$ & $11-15$ & $16-20$ & $21-25$ & $>25$ & Total (\%) \\
\hline Catholic University of Leuven & 13 & 11 & 21 & 29 & 18 & 22 & $114(37.1)$ \\
Ghent University & 12 & 23 & 21 & 28 & 28 & 24 & $136(44.3)$ \\
Free University of Brussels & 10 & 15 & 12 & 9 & 4 & 4 & $54(17.6)$ \\
Catholic University of Louvain & - & - & - & 1 & - & - & $1(0.3)$ \\
Other & - & - & - & 2 & - & - & $2(0.7)$ \\
Total (\%) & $35(11.4)$ & $49(16.0)$ & $54(17.6)$ & $69(22.5)$ & $50(16.3)$ & $50(16.3)$ & 307 \\
\hline
\end{tabular}

Table 2 Distribution of the respondents by clinical interest

\begin{tabular}{lrr}
\hline & \multicolumn{1}{l}{$n$} & \multicolumn{1}{l}{$\%$} \\
\hline General practitioner & 263 & 85.7 \\
General practitioner without clinical interest & 228 & 74.3 \\
General practitioner with clinical interest & 35 & 11.4 \\
Endodontics & 6 & 2.0 \\
Aesthetics & 7 & 2.3 \\
Orthodontics & 13 & 4.2 \\
Periodontics & 3 & 1.0 \\
Paediatric dentistry & 5 & 1.6 \\
Prosthodontics & 10 & 3.3 \\
Other & 2 & 0.7 \\
Specialist practice (exclusive) & 44 & 14.3 \\
Endodontics & 4 & 1.3 \\
Aesthetics & 6 & 2.0 \\
Orthodontics & 10 & 3.3 \\
Periodontics & 6 & 2.0 \\
Paediatric dentistry & 15 & 4.9 \\
Prosthodontics & 12 & 3.9 \\
Other & 2 & 0.7 \\
\hline
\end{tabular}

distribution of the respondents according to their clinical speciality (preference) in practice. The majority $(85.7 \%)$ of the respondents labelled themselves as general practitioners. Twenty-six percent of the respondents mentioned a clinical speciality (preference) in practice. Thirty-five $(11.4 \%)$ respondents were general practitioners with a special interest (Table 2). The practitioners with a true specialist practice accounted for $14.3 \%$ of the sample (44 respondents). Most practitioners reported having no special clinical interest in their practice $(74.3 \%)$.

\section{General information about endodontic treatment}

\section{Rubber dam}

The majority (64.5\%) of individuals never or seldom used rubber dam, $20.5 \%$ of the sample used rubber dam in a limited number of cases and only $7.2 \%$ used rubber dam in all cases. The time since graduation had no statistically significant effect $\left(P=0.054, \chi^{2}=18.1\right)$ on use of rubber dam.

Frequency of root canal treatment and number of visits per treatment

The number of root canal treatments performed in 1 week ranged from 1-9, with an average of 4.8 and a mode of 7 (Table 3). There was no statistically significant influence of the period since qualification on the number of root canal treatments performed per week.

A summary of the number of visits to complete treatment in relation to the number of root canals in a tooth is depicted in Fig. 1. There was a clear trend towards more visits when more canals were to be treated. Most root

Table 3 Distribution of the respondents according to the number of root canal treatments (RCT) per week and the period following qualification

\begin{tabular}{|c|c|c|c|c|c|c|c|c|c|c|}
\hline \multirow{2}{*}{$\begin{array}{l}\text { Period following } \\
\text { qualification }\end{array}$} & \multicolumn{9}{|c|}{ RCT per week } & \multirow[b]{2}{*}{ No answer } \\
\hline & 1 & 2 & 3 & 4 & 5 & 6 & 7 & 8 & 9 & \\
\hline $0-5$ & 3 & 6 & 4 & 4 & 4 & 5 & 4 & 4 & - & 1 \\
\hline $6-10$ & 3 & 6 & 4 & 9 & 7 & 7 & 11 & 2 & - & - \\
\hline $11-15$ & 3 & 3 & 6 & 5 & 7 & 7 & 18 & 4 & - & 1 \\
\hline $16-20$ & 2 & 5 & 12 & 6 & 3 & 14 & 18 & 3 & 2 & 4 \\
\hline $21-25$ & 3 & 6 & 9 & 11 & 5 & 4 & 10 & 2 & - & - \\
\hline$>25$ & 3 & 6 & 9 & 3 & 4 & 12 & 8 & 4 & - & 1 \\
\hline Total (\%) & $17(5.5)$ & $32(10.4)$ & 44 (14.3) & 38 (12.4) & $30(9.8)$ & 49 (16.0) & $69(22.5)$ & $19(6.2)$ & $2(0.7)$ & $7(2.3)$ \\
\hline
\end{tabular}




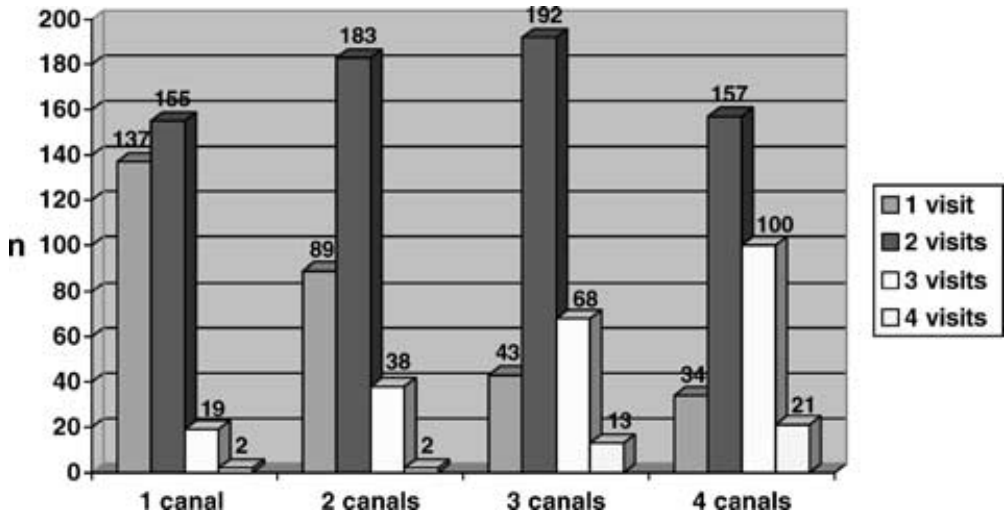

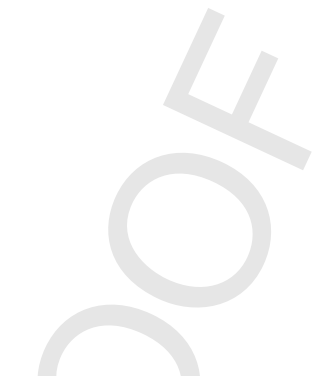

Figure 1 Number of visits according to the number of root canals per tooth. canal treatments were performed within two visits, even for single rooted teeth. There were no statistically significant differences between the different periods following graduation and the number of visits taken to complete a root filling.

\section{Anatomical variations}

The percentage of fourth canals (second mesiobuccal canal) treated in maxillary first and second molars and C-shaped root canal system treated in mandibular molars is described inTable 4. The majority of the respondents seldom treated the second mesiobuccal canal in maxillary molars, nor were aware of $\mathrm{C}$-shaped mandibular first molars. Approximately $18 \%$ of the respondents did not respond to the question concerning C-shaped mandibular molars.

\section{Cleaning and shaping}

\section{Irrigation and medication}

Sodium hypochlorite was the most popular choice as a canal irrigant with $82.4 \%$ of the respondents using it during treatment; of that total $70.4 \%$ used only sodium hypochlorite, whereas $29.6 \%$ used it along with other irrigants. The irrigants used besides sodium hypochlorite were chloramine $(16.6 \%)$, chlorhexidine $(7.5 \%)$, distilled water $(2.6 \%)$, hydrogen peroxide $(11.1 \%)$ and saline $(6.8 \%)$. The time since graduation did not statistically significantly influence the choice of the irrigant.

The most popular concentration of sodium hypochlorite was $2.5 \%$ (39.1\% of respondents that used sodium hypochlorite), with $2 \%$ using a $0.5 \%$ solution, $3.6 \%$ using $1 \%, 4.9 \%$ using $1.5 \%, 22.1 \%$ using $2 \%$ and $9.1 \%$ using $5 \%$ solution. Of the respondents that used sodium hypochlorite, $10.6 \%$ did not answer or did not know the concentration of sodium hypochlorite they used. Seven percent used two or more concentrations.

Of the practitioners irrigating root canals with sodium hypochlorite, $68.9 \%$ never used rubber dam, $22.3 \%$ used rubber dam in a limited number of cases and $8.8 \%$ used rubber dam in all cases.

EDTA was used by $61.6 \%$ of the respondents in a variety of formulations. A liquid EDTA solution was used by $12.4 \%$, File-Eze (Ultradent Products Inc., South Jordan, UT, USA) by $13.4 \%$, Rc-prep (Premier Dental Products Co., King of Prussia, PA, USA) by $32.9 \%$ and $7.2 \%$ used other formulations. Of the practitioners that

\begin{tabular}{llrl}
\hline & \multicolumn{2}{l}{ Number of respondents scoring the prevalence of } \\
\cline { 2 - 4 } Prevalence (\%) & Four canals in maxillary & Four canals in maxillary & C-shaped canal in \\
first molar & second molar & 238 \\
\hline $0-25$ & 279 & 291 & 45 \\
0 & 18 & 84 & 61 \\
1 & 67 & 91 & 65 \\
$2-5$ & 87 & 69 & 37 \\
$6-10$ & 62 & 35 & 16 \\
$11-20$ & 24 & 10 & 14 \\
$21-25$ & 21 & 2 & 9 \\
$26-50$ & 11 & 3 & 4 \\
$51-75$ & 8 & 0 & 2 \\
$76-100$ & 3 & 2 & 54 \\
No answer & 6 & 11 & \\
\hline
\end{tabular}

Table 4 Awareness of specific anatomical variations by respondent 
used EDTA, 87.8\% combined the chelator with sodium hypochlorite. There was no significant relationship between the use of EDTA and the time after graduation.

\section{Working distance}

Most practitioners used radiographs for length determination. The most common apical limit of preparation was $1 \mathrm{~mm}$ short of the radiographic apex (44.3\%), followed by $0.5 \mathrm{~mm}$ short of the radiographic apex (19.9\%). Only $1.6 \%$ of respondents used a working distance $0.5 \mathrm{~mm}$ beyond the radiographic apex, whilst $16.9 \%$ prepared as far as the radiographic apex. An apical terminus located $1.5 \mathrm{~mm}$ short of the radiographic apex was chosen by $16.0 \%$ of the practitioners and only $3.9 \%$ ended the canal preparation 2-3 mm short of the radiographic apex. A small proportion (3.6\%) relied on tactile sense for length determination, all of these had graduated for more than 10 years.

The use of electronic apex locators was limited with $16.0 \%$ of the practitioners using it occasionally and $4.9 \%$ seldomly. Approximately $80 \%$ of the respondents never used electronic length determination. There was no statistically significant difference in the use of electronic apex locators in relation to the time after graduation.

\section{Instruments}

Table 5 gives an overview of the hand instruments used for preparation of the root canal by time since qualification. Overall, K-files were the most popular instruments. Root canal preparation solely with K-files or in combination with other instruments was performed by $60.3 \%$ of the respondents, followed by $55.4 \%$ that used reamers (solely or in combination), H-files (solely or in combination) by $46.9 \%$ of the respondents and $19.2 \%$ of the respondents combined K-files and reamers during root canal preparation. $\mathrm{Ni}-\mathrm{Ti}$ hand files were used by $49.5 \%$ of the practitioners. There was a statistically significant difference in usage of instruments as related to the time after graduation $\left(P=0.039, \chi^{2}=44.9\right)$. The older practitioners tended to use reamers more than their younger colleagues.

\section{Rotary instruments}

Engine-driven instruments were used by $27.7 \%$ of the respondents. There was no difference between the different qualification-time groups regarding the frequency of use of engine driven instruments.

The practitioners were familiar with the following instruments: Profile (71.3\%; Dentsply Maillefer, Ballaigues, Switzerland), Ultrasonic files (53.4\%), Files of Greater Taper (39.1\%; Dentsply Tulsa Dental, Tulsa, OH, USA), Safety H-files (30.9\%; Kerr-Sybron, West Collins Orange, CA, USA), Lightspeed (10.7\%; Lightspeed Technology Inc., San Antonio, TX, USA) and Quantec (3.6\%; Sybron endo, West Collins Orange, CA, USA).

Of the respondents, $64.5 \%$ used only hand files for root canal preparation, $26.0 \%$ used a combination of hand files and rotary instruments and $1.6 \%$ used only rotary instruments.

\section{Preparation techniques}

Table 6 gives an overview of the instruments used by the different preparation techniques. Almost one-third of the practitioners (31.9\%) stated that they used the stepback technique, followed by $26.4 \%$ for the combination of stepdown and stepback, and $26.1 \%$ for a reaming technique. The stepdown technique was used by $14.7 \%$ of the respondents. The technique used differed significantly between the qualification-time groups $(P<0.05)$. Reaming was used more by the older practitioners (group 4), stepback and stepdown were used equally by all age groups.

The relation between the technique used to prepare the root canal and the number of root canal treatments performed per week is described in Table 7. There were no statistically significant differences between the
Table 5 Number of respondents using the various endodontic instruments by time since graduation

\begin{tabular}{lccccccc}
\hline \multirow{2}{*}{ Instruments } & \multicolumn{7}{c}{ Years of qualification } \\
\cline { 2 - 6 } & $0-5$ & $6-10$ & $11-15$ & $16-20$ & $21-25$ & $>25$ & Total (\%) \\
\hline Reamer & 2 & 3 & 5 & 6 & 4 & 3 & $23(7.5)$ \\
K-file & 11 & 7 & 12 & 10 & 6 & 6 & $52(16.9)$ \\
H-file & 3 & 3 & 2 & 8 & 5 & 4 & $25(8.1)$ \\
Reamer + K-file & 2 & 9 & 9 & 9 & 13 & 17 & $59(19.2)$ \\
Reamer + H-file & 3 & 7 & 7 & 15 & 6 & 7 & $45(14.7)$ \\
K-file + H-file & 6 & 12 & 6 & 3 & 3 & 1 & $31(10.1)$ \\
Reamer + K-file + H-file & 6 & 5 & 6 & 11 & 8 & 7 & $43(14.0)$ \\
No answer & 2 & 3 & 7 & 7 & 5 & 5 & $29(9.4)$ \\
Total & 35 & 49 & 54 & 69 & 50 & 50 & $307(100)$ \\
\hline
\end{tabular}




\begin{tabular}{|c|c|c|c|c|c|}
\hline \multirow[b]{2}{*}{ Endodontic instruments } & \multicolumn{5}{|c|}{ Preparation technique } \\
\hline & Reaming & Stepback & Stepdown & $\begin{array}{l}\text { Stepdown }+ \\
\text { stepback }\end{array}$ & Other \\
\hline Reamer & 9 & 10 & 3 & 2 & 2 \\
\hline K-file & 1 & 19 & 12 & 23 & 4 \\
\hline $\mathrm{H}$-file & 7 & 13 & 1 & 6 & 1 \\
\hline Reamer + K-file & 24 & 13 & 5 & 19 & 1 \\
\hline Reamer $+\mathrm{H}$-file & 22 & 16 & 4 & 5 & 0 \\
\hline K-file $+\mathrm{H}$-file & 3 & 9 & 7 & 11 & 2 \\
\hline Reamer $+\mathrm{K}$-file $+\mathrm{H}$-file & 13 & 16 & 7 & 12 & 0 \\
\hline No answer & 1 & 2 & 6 & 3 & 0 \\
\hline Total (\%) & $80(26.1)$ & 98 (31.9) & 45 (14.7) & $81(26.4)$ & $10(3.3)$ \\
\hline
\end{tabular}

\begin{tabular}{|c|c|c|c|c|c|c|c|c|c|c|}
\hline \multirow[b]{2}{*}{ Preparation technique } & \multicolumn{9}{|c|}{$\mathrm{RCT}$} & \multirow[b]{2}{*}{ Tota } \\
\hline & 1 & 2 & 3 & 4 & 5 & 6 & 7 & 8 & 9 & \\
\hline Reaming & 1 & 6 & 16 & 11 & 7 & 14 & 18 & 3 & 1 & 77 \\
\hline Stepback (SB) & 2 & 17 & 13 & 12 & 7 & 15 & 20 & 9 & 1 & 96 \\
\hline Stepdown (SD) & 1 & 4 & 4 & 8 & 3 & 10 & 11 & 2 & - & 43 \\
\hline $\mathrm{SB}+\mathrm{SD}$ & 3 & 8 & 13 & 6 & 11 & 11 & 22 & 6 & 1 & 81 \\
\hline Other & - & 0 & 1 & 2 & 2 & - & 4 & 1 & - & 10 \\
\hline
\end{tabular}

preparation techniques and the number of root canals per week.

The questionnaire also requested whether the following techniques were known by the respondents (positive responses between parentheses): crown-down (45.0\%), balanced force or Roane technique (31.6\%), crown-down pressureless technique $(20.2 \%)$ and modified doubleflared technique $(19.5 \%)$. There were no statistically significant differences between the different qualification-time groups regarding knowledge of these techniques.

A large proportion (44.3\%) of the respondents were satisfied with the preparation technique (rotary or hand instrumentation) they used in daily practice, $48.2 \%$ felt that their root canal preparations could be improved and $1.3 \%$ were completely dissatisfied with their root canal preparations.

\section{Discussion}

All persons participating in this study were attending a formal peer review session. These peer review activities are part of an accreditation system in which $60 \%$ of the Flemish practitioners take part. The distribution of the age groups reflected the age distribution of the Flemish dental profession, with the greater number of graduates in the 1980s. Therefore, the group selected is likely to be representative of the general dental population in the Flemish part of Belgium. The group was represented by graduates from all Flemish universities.
Table 6 Number of respondents using the various endodontic instruments by preparation techniques

The response rate was high, which would be expected when questionnaires are handed out personally and collected immediately after completion. This is in contrast with postal surveys where the response rates are generally lower. The majority of the respondents were general practitioners $(85.7 \%)$, reflecting the fact that this is the area where the majority of dental treatment is provided in Belgium.

The use of rubber dam by Belgian dental practitioners was low. Only $7 \%$ of the practitioners used rubber dam in all cases, even though the use of rubber dam is taught in every dental school in Flanders. These results agree with other recent studies (Saunders et al. 1999, Whitworth et al. 2000, Jenkins et al. 2001). There was no relation between the use of rubber dam and the time after graduation, indicating that its use in daily dental practice is abandoned quickly.

The majority of root canal treatments was carried out in two visits, even for teeth with single root canals. Similar results were found by Saunders et al. (1999) who studied general dental practitioners in Great Britain and Inamoto et al. (2002) with questionnaires sent to endodontists in the USA. The increased number of visits necessary for the treatment of multiple canals reflected the complexity of treating such cases. The number of appointments required for treatment is a matter of debate. One-visit root canal treatment is not encouraged for necrotic pulps (Sjögren et al. 1997, Trope et al. 1999), however, it could be argued that with more visits, the risk of 
contamination increases, especially in cases with more than two visits.

The majority of practitioners did not treat the fourth canal in maxillary first and second molars, even though it may be present in at least $60 \%$ of the maxillary first and second molars (Okumura 1927, Kulild \& Peters 1990). Furthermore, approximately one-fifth of the respondents did not respond to the question on treating a C-shape in mandibular molars. We assume that the majority of the present practitioners were not aware of the true meaning of the $\mathrm{C}$-shape in mandibular molars. A C-shaped root canal system is present in approximately $8 \%$ of the mandibular second molars (Cooke \& Cox 1979, Weine 1998). The practitioners indicating treatment of $\mathrm{C}$-shapes in over $50 \%$ probably had misinterpreted the question and saw the C-shape as a kidney-shaped distal canal in lower molars. This became clear when the subject of $\mathrm{C}$-shapes was discussed during the peer review sessions.

In this study sodium hypochlorite was most popular amongst most of the practitioners; in concentrations up to $5 \%$, it was used in $82.4 \%$ of cases. Sodium hypochlorite combined with hydrogen peroxide and chlorhexidine has been described in the literature (Ingle \& Bakland 1994) although the combination of sodium hypochlorite and hydrogen peroxide is not recommended (Harrison et al.1978). Furthermore, the use of irrigants such as chloramine and saline are not recommended for endodontic use (Ingle \& Bakland 1994, Heling \& Chandler 1998) as they do not have the antimicrobial and tissue solving capacities of a sodium hypochlorite solution. A possible reason for not using sodium hypochlorite and using a weak solution may be related to the limited use of rubber dam (Saunders et al. 1999, Whitworth et al. 2000, Jenkins et al. 2001), but was not the case in the present study.

Correct estimation of the length of the root canal is essential and this can be established by tactile sense, using radiographs and/or by electronic devices. Radiographs with an instrument of known length in situ were used for length determination by virtually all respondents. Only a minority $(3.5 \%)$ relied on tactile sense for estimation of the working length. This method is not recommended since it does not give reliable results due to anatomical obstructions and constrictions in the

[Q1] canals (Dummer 1984). There was no subdivision in the question concerning the influence of tooth vitality (vital vs. necrotic pulps), but the results indicated that the majority of the respondents was aiming for a working length 1-2 mm short of the radiographic apex. Recent advances in endodontics have led to improved reliability of electronic length determination (De Moor et al. 1999). However, these devices were not often used (20\%).

K-files were the hand instruments of choice for root canal preparation for most of the practitioners. They were used solely or in combination with other root canal instruments. Reamers, although abandoned by many schools for routine preparation, were still used by more than half of the practitioners; $\mathrm{H}$-files and $\mathrm{Ni}-\mathrm{Ti}$ files were also widely used.

Ingle (1961) described a standardized method for root canal instrumentation and preparation, utilizing instruments of fixed size and taper, with matching points for obturation. This technique was taught widely and is known to be widely practised (Carrotte 2000b). Although he did not actually use the term 'stepback', Schilder (1974) described the sequential widening of the apical part of the canal and the technique was rapidly adopted and further developed. The data in the present study showed that a great number of the older practitioners still used the standardized method, though it was interesting to see that the stepback technique with or without orifice enlargement was well established. This finding is in contrast with the findings of Jenkins et al. (2001) who showed that in their study practitioners tended to use the technique they were taught. Apparently, the stepdown/stepback approach, which is taught at the Flemish universities during present-day undergraduate programmes and during postgraduate courses, was adopted by the majority of the practitioners participating in this study. Preparation techniques such as the crown-down technique, balanced force technique, crown-down pressureless technique or modified double-flared technique were not commonly used and were only known by a minority of the practitioners. This finding emphasizes the need for continuing postgraduate training in endodontics.

About one-third of the respondents were familiar with the more modern preparation techniques but it was clear that each of the presently available systems was different with various techniques and products. In this respect, an interesting finding was that about half of the respondents felt their root canal preparation could be improved. A small minority were dissatisfied with the result of the preparation technique.

\section{Conclusion}

It is clear that a large percentage of dentists, irrespective of the time since graduation, relied on techniques and used products and materials which are currently favoured by expert opinion. Nonetheless, half of the present 
group seemed not to be satisfied with their preparation technique.

\section{References}

Carrotte PV (2000a) Current Practice in Endodontics. Dental Update 27, 338-40.

Carrotte PV (2000b) Current Practice in Endodontics. Part 4. A review of techniques for canal preparation. Dental Update 27, 488-93.

Cooke HG, Cox FL (1979) C-shaped canal configurations in mandibular molars. Journal of the American Dental Association 99, 836-9.

De Moor RJG, Hommez GMG, De Boever JG, Martens GEI, Delmé KIM (2000) Periapical health related to the quality of root canal treatment in a Belgian population. International Endodontic Journal 33, 113-20.

De Moor RJG, Hommez GMG, Martens LC, De Boever JG (1999) Accuracy of four electronic apex locators: an in vitro evaluation. Endodontics and Dental Traumatology 15, 77-82.

Dummer PMH (1984) The position and topography of the apical constriction and apical foramen. International Endodontic Journal 17, 192-8.

Dummer PMH (1991) Comparison of undergraduate endodontic teaching programmes in the United Kingdom and some dental schools in Europe and the United States. International Endodontic Journal 24, 169-77.

European Society of Endodontology (2001) Undergraduate curriculum guidelines for endodontology. International Endodontic Journal 34, 574-80.

HarrisonJW, SvecTA, BaumgartnerJC (1978) Analysis of clinical toxicity of endodontic irrigants. Journal of Endodontics 4, 6-11.

Heling I, Chandler NP (1998) Antimicrobial effect of irrigant combinations within dental tubules. International Endodontic Journal 31, 8-14.

Hommez GMG, Coppens CRM, De Moor RJG (2002) Periapical health related to the quality of coronal restorations and root fillings. International Endodontic Journal 35, 680-9.

Inamoto K, Kojima K, Nagamatsu K, Hamaguchi A, Nakata K, Nakamura H (2002) A survey of the incidence of single-visit endodontics. Journal of Endodontics 28, 371-4.

Ingle JL (1961) A standardized endodontic technique utilizing newly designed instruments and filling materials. Oral Surgery Oral Medicine Oral Pathology 14, 83-91.
Ingle JI, Bakland LK (1994) Endodontics, 4th edn. Malvern, PA, USA: Williams \& Wilkins.

Jenkins SM, Hayes SJ, Dummer PMH (2001) A study of endodontic treatment carried out in dental practice within the UK. International Endodontic Journal 34, 16-22.

Kirkevang LL, Hörsted-Bindslev P, Ørstavik D, Wenzel A (2001) Frequency and distribution of endodontically treated teeth and apical periodontitis in an urban Danish population. International Endodontic Journal 34, 198-205.

Kulild JC, Peters DD (1990) Incidence and configuration of canal systems in the mesiobuccal root of maxillary first and second molars. Journal of Endodontics 16, 311-7.

Marques MD, Moreira B, Eriksen HM (1998) Prevalence of apical periodontitis and results of endodontic treatment in an adult, Portuguese population. International Endodontic Journal 31, $161-5$.

Okumura T (1927) Anatomy of the root canals. Journal of the American Dental Association 1927, 632-6.

SaundersWP, Chestnutt IG, Saunders EM(1999) Factors influencing the diagnosis and management of teeth with pulpal and periradicular disease by general dental practitioners. Part 2. British Dental Journal 187, 548-54.

Saunders WP, Saunders EM, Sadiq J, Cruickshank E (1997) Technical standard of root canal treatment in an adult Scottish population. British Dental Journal 183, 383-6.

Schilder H (1974) Cleaning and shaping of the root canal. Dental Clinics of North America 18, 269-74.

Sjögren U, Figdor D, Persson S, Sundqvist G (1997) Influence of infection at the time of root filling on the outcome of endodontic treatment of teeth with apical periodontitis. International Endodontic Journal 30, 297-306.

Trope M, Deleano EO, Ørstavik D (1999) Endodontic treatment of teeth with apical periodontitis: single versus multivisit treatment. Journal of Endodontics 25, 345-50.

Weiger R, Hitzler S, Hermle G, Löst C (1997) Periapical status, quality of root canal fillings and estimated endodontic treatment needs in an urban German population. Endodontics and Dental Traumatology 13, 69-74.

Weine FS (1998) The C-shaped mandibular second molar: incidence and other considerations. Journal of Endodontics 24, 372-5.

Whitworth JM, Seccombe GV, Shoker K, Steele JG (2000) Use of rubber dam and irrigant selection in UK general dental practice. International Endodontic Journal 33, 435-41. 


\section{AUTHOR QUERY FORM}

Dear Author,

During the copy-editing of your paper, the following queries arose. Please respond to these by marking up your proofs with the necessary changes/additions. Please write your answers on the query sheet if there is insufficient space on the page proofs. Please write clearly and follow the conventions shown on the attached corrections sheet. If returning the proof by fax do not write too close to the paper's edge. Please remember that illegible mark-ups may delay publication.

\begin{tabular}{|l|l|l|}
\hline $\begin{array}{l}\text { Query } \\
\text { References }\end{array}$ & Query & Remarks \\
\hline 1 & $\begin{array}{l}\text { Dummer et al. } \mathbf{1 9 8 4} \text { has been changed to } \\
\text { Dummer 1984 so that this citation matches the list }\end{array}$ & \\
\hline
\end{tabular}




\section{Please correct and return this set}

Any errors in this proof which have been noticed by the printer's reader have been marked in green. If you see any more printer's errors, please mark them in red: there is no charge for correcting these mistakes. For your own alterations, please use black or blue or any colour other than green or red. Please use the proof correction marks shown below for all alterations and corrections.

\begin{tabular}{|c|c|c|}
\hline Instruction to printer & Textual mark & Marginal mark \\
\hline Leave unchanged & ... under matter to remain & Stet \\
\hline $\begin{array}{l}\text { Insert in text the matter } \\
\text { indicated in the margin }\end{array}$ & $h$ & $\begin{array}{l}\text { New matter followed by } \\
\boldsymbol{h}\end{array}$ \\
\hline Delete & $\mapsto$ through matter to be deleted & d] \\
\hline Delete and close up & E through matter to be deleted & मी \\
\hline $\begin{array}{l}\text { Substitute character or } \\
\text { substitute part of one or } \\
\text { more word(s) }\end{array}$ & $\begin{array}{l}\text { / through letter or } \mapsto \text { through } \\
\text { word }\end{array}$ & New letter or new word \\
\hline Change to italics & - under matter to be changed & س山 \\
\hline Change to capitals & $\equiv$ under matter to be changed & $\equiv$ \\
\hline Change to small capitals & $=$ under matter to be changed & $=$ \\
\hline Change to bold type & u under matter to be changed & $m$ \\
\hline Change to bold italic & $\bar{\approx}$ under matter to be changed & \\
\hline Change to lower case & Encircle matter to be changed & $\nRightarrow$ \\
\hline Change italic to upright type & (As above) & $\psi$ \\
\hline Insert 'superior' character & $\begin{array}{l}\text { / through character or } \wedge \text { where } \\
\text { required }\end{array}$ & $\begin{array}{l}y \text { under character } \\
\text { e.g. } y\end{array}$ \\
\hline Insert 'inferior' character & (As above) & $L$ over character e.g. $\frac{2}{2}$ \\
\hline Insert full stop & (As above & $\circ$ \\
\hline Insert comma & (As above) & , \\
\hline Insert single quotation marks & (As above) & $y$ and/or $y$ \\
\hline $\begin{array}{l}\text { Insert double quotation } \\
\text { marks }\end{array}$ & (As above) & 'y and/or $y$ \\
\hline Insert hyphen & (As above) & (4y) \\
\hline Start new paragraph & $r$ & $\sqrt{5}$ \\
\hline No new paragraph & 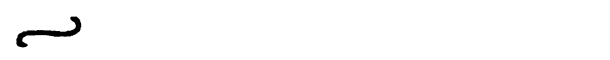 & 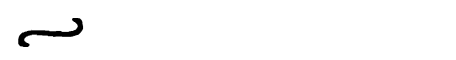 \\
\hline Transpose & $\sqrt{\sim}$ & $\sqrt{-1}$ \\
\hline Close up & linking $\approx$ letters & $=$ \\
\hline Insert space between letters & $\Lambda$ between letters affected & \# \\
\hline Insert space between words & $\boldsymbol{h}$ between words affected & \# \\
\hline Reduce space between letters & $\uparrow$ between letters affected & $T$ \\
\hline Reduce space between words & $\boldsymbol{\top}$ between words affected & \\
\hline
\end{tabular}

